\title{
Niemann-Pick Disease, Type C
}

National Cancer Institute

\section{Source}

National Cancer Institute. Niemann-Pick Disease, Type C. NCI Thesaurus. Code C85214.

An autosomal recessive inherited lysosomal storage disease caused by mutations in the NPC1 and NPC2 genes. It is characterized by progressive neurologic deterioration manifested with ataxia, dementia, seizures, and dystonia. Other signs and symptoms include hepatosplenomegaly, jaundice, and respiratory failure. 